\title{
Die personaliteit van vrou-wees binne die Mediterreense kultuur
}

\author{
Yolanda Dreyer \\ Tydelik-deeltydse dosent: \\ Departement Nuwe-Testamentiese Wetenskap (Afd A) \\ Universiteit van Pretoria
}

\begin{abstract}
Being a woman in Mediterranean culture

This article is written from the perspective of pastoral care and counseling with women. On account of their training in Biblical studies, pastors are aware of the gap between modern Western culture and Mediterranean culture in the first century. The question is whether the meaning of this knowledge for the life and faith of women is adequately taken into consideration in pastoral work. In this article an explanation of what is meant by the concept 'culture' is given. The meaning of social identity within Mediterranean culture, being a woman within first-century patriarchy and the different 'categories' of women in this culture are discussed. These aspects are contextualised within the purity system of that culture.
\end{abstract}

\section{VOORAF OPMERKINGS}

Wat pastoraat met vroue binne die ruimte van 'n Reformatoriese kerk betref, is die gebruik van die Skrif as die kerk se klassieke model van oriëntering vanselfsprekend. 'n Ondersoek van die eerste-eeuse Mediterreense kultuur ten opsigte van die plek en rol van vroue, die familie en die huwelik is dus onontbeerlik vir teologiese refleksie op die pastorale interaksie met vroue. Soos wat die patriargaat sedert die aanbreek van die moderne paradigma verander het en geleidelik getemper is as gevolg van minder rigiede geslagsrolle, groter gelykheid tussen die geslagte en 'n waarborg van menseregte vir alle mense, word dit al hoe meer nodig om vir die pastoraat met vroue 'n Skriftuurlike grondslag te vind 'which yields more than outdated wisdom dependent upon irrelevant analogies' (Jacobs-Malina 1993:9). Dianne Jacobs-Malina wys daarop dat Hebreeuse epiese literatuur, Griekse filosofie en Romeinse reg wat nou verweef is met patriargale dominansie, toenemend irrelevant word vir Christene. Volgens haar is dit nodig om in die Skrif dié sake te vind wat tyd en kultuur oorstyg. Die norme en doel- 
witte van die evangelie sal dan steeds relevant kan bly vir menslike gedrag lank nadat die patriargale perspektief finaal verdwyn het (Jacobs-Malina 1993:9).

Aangesien die pastor en lidmaat nie ten doel het om 'n antieke kultuur en sosiale gebruike as normatief in die eietydse geskiedenis oor te dra nie, moet Christelike norme, waardes en riglyne vir outentieke geloofslewe op 'n verantwoordelike wyse vanuit die Nuwe Testament as 't ware 'vertaal' word in die denke, kultuur en leefwyse van die moderne mens. Dit is dus 'n hermeneutiese proses.

If those writings [die Nuwe Testament] are to resonate in our different cultural contexts, if faith is to be held responsibly, then theology will have to carry out its work of articulating the culture-bound, original symbols of the primordial Christian movement in terms of the clearest language and models that it can find in the cultures in which it is to be expressed, understood, and lived out.

(Malina [1981] 1993:185)

In 'n vorige artikel (Dreyer 1998:633-634, 641-645) het ek wat die feministiese hermeneutiek betref, ingegaan op veral twee opsies rakende 'n Skrifbeskouing: 'n revolusionêre benadering (wat die ommekeer van sosiale rolle ten doel het) en betrokke hermeneutiek (wat 'n bewusmakingsproses met betrekking tot die skade wat aan vroue berokken kan word as gevolg van manlike oorheersing). Ek het vir laasgenoemide gekies. In die verdere onderbouing van hierdie siening wil ek in twee opeenvolgende artikels aandag gee aan die Jesus-saak as uitgangspunt vir pastoraat met vroue. Dit beteken vir my dat ek in my soeke na Jesus veral geinteresseerd is in die sosio-historiese konteks van die historiese Jesus en van die Nuwe Testament as 'n versameling geloofsgetuienisse oor Jesus. Predikante wat nie beskik oor 'n besondere belangstelling in die Nuwe Testament, en spesifiek in die sosiaal-wetenskaplike kritiek wat onlangs sterk onder die aandag van eksegete gekom het nie, sal miskien nie so kultuur bewus met die Nuwe Testament omgaan nie. Dit is juis die sosiaal-wetenskaplike kritiek wat ons deesdae weer bewus makk van die afstand tussen die leefwêreld van die Bybel en ons moderne samelewing. Die vraag is of pastors wat wel bewus is van die groot gaping tussen die moderne Westerse kultuur en die eerste-eeuse Mediterreense kultuur, genoegsaam in die gemeente en in die pastoraat fokus op die betekenis wat hierdie verskille vir die lewens en geloof van vroue inhou.

In 'n poging om iets vir vroue te herwin uit 'n antieke tradisie waarin vroue feitlik onsigbaar en beslis stemloos was (Bach 1993:195), gebeur dit dat die antieke teks en 
kultuur nie altyd in eie reg beoordeel word nie, maar ook vanuit hedendaagse belange benader word. Hierdie verskynsel van misplaaste konkretisering word 'etnosentrisme' en 'anachronisme' genoem. Bruce Malina (1993:11) verduidelik dit as: 'interpreting other's actions in terms of my own behavior and my own time' (my beklemtoning). In haar bespreking van die feministiese teoloë wat ten doel het om 'n samehangende patroon te vind in die profiele van vroue in die Bybel, meen Alice Bach (1993:200) dat die poging onmoontlik suksesvol kan wees, tensy sowel die betekenis van sosiale en kulturele kodes as die geslagskodes wat die tekste reflekteer, duidelik blootgelê word.

In 'n volgende artikel wil ek spesifiek aandag gee aan Jesus se houding teenoor vroue. Hierdie artikel het ten doel om die sosiale en kulturele milieu waarbinne Jesus van Nasaret geleef en gewerk het en waarbinne die Nuwe Testament as die 'boek van die kerk' aanvanklik gekommunikeer het, te ondersoek. Die fokus van die artikel val op die sosiale posisie van vroue en die kulturele verwagtings en vooronderstellings ten opsigte van vroue. Die volgende artikel sal handel oor die vraag hoe Jesus te midde van hierdie sosiale en kulturele klimaat met die patriargale sisteem en met vroue omgegaan het, en die betekenis van sy optrede vir die sosiale opset, die kultuur en die vroue van sy tyd. Albei artikels wil deur middel van 'n verantwoordelike hermeneutiek, wat volledig erns maak met sowel die sosiale sisteem van die eerste-eeuse Mediterreense wêreld as die sosiale sisteem en kultuur van die moderne Westerling, bepaal wat die betekenis van Jesus se optrede in die eerste eeu kan wees vir gelowige vroue vandag. In die eerste artikel gaan ek in op aspekte soos 'n definisie van kultuur, wat identiteit binne die Mediterreense kultuur behels, die personaliteit van vrou-wees binne 'n patriargale kultuur en die verskillende 'kategorieè' van vroue wat in hierdie kultuur onderskei kan word. In die tweede artikel val die klem op Jesus van Nasaret.

\section{SISTEEM VAN SIMBOLE EN SOSIALE GEDRAG}

Om duidelikheid te kry oor die eerste-eeuse Mediterreense kultuur gee ek eers aandag die begrip 'kultuur'. My verstaan van hierdie begrip is dialekties georiënteer en ek laat my lei deur veral die insigte van Wuthnow et al (1987). Die dialektiek bestaan uit die onlosmaaklike verband tussen die teoretiese (sisteem van simbole) en die praktiese (sosiale gedrag). 'n Mens kan kultuur sien as 'n georganiseerde sisteem van simbole waarvolgens ' $n$ spesifieke en sosiaal-bepaalde stel betekenisse en waardes aan persone, dinge en gebeurtenisse toegeken word. Kulture skep patrone van gedeelde betekenis en gevoel. Hierdie patrone vorm op hulle beurt die sosiale wêreld van 'n spesifieke groep mense (vgl Malina 1993:9). Simbole ken betekenis en waarde (gevoel) op só 'n manier aan mense, dinge en gebeurtenisse toe dat al die lede van 'n gegewe groep hierdie 
betekenis en waardes gewoonlik onkrities aanvaar, met mekaar deel en op 'n manier uitleef (Malina 1993:12). Daarom bepaal die kultuur en sosiale sisteem waarbinne 'n persoon leef, onbewustelik sy of haar beskouing van die lewe en die werklikheid (Malina 1993:13).

As 'n persoon geen ander kulture ken nie, word die eie kultuur nie raakgesien as relatief nie, maar as die totale werklikheid beleef. Selfs wanneer iemand bewus is van denkverskille, betekenisverskille en verskillende gebruike en gewoontes tussen kulture, is dit steeds moeilik om die eie kultuur se dinkpatrone en vooronderstellings af te skakel met die lees van literatuur uit 'n ander kultuur. Dit geld ook vir die lees van die Bybel deur mense in 'n moderne, Westerse kultuur. In kerke in die Reformatoriese tradisie in Suid-Afrika word die Bybel as normatief vir die gelowige se lewe gereken. Dit volg dus dat die mense wat binne 'n moderne, Westerse kultuur leef, predikante sowel as lidmate, hierdie norm sal interpreteer en toepas vanuit 'n perspektief wat deur die eie kultuur bepaal word, tensy daar 'n bewuste poging aangewend word om die kultuur van die eerste eeuse-Mediterreense wêreld te begryp. Die interpretasie van tekste uit 'n wereld waar die kultuur drasties verskil van diê van die interpreteerder, vereis insig in die relatiwiteit van die eie kultuur en in 'n sekere sin die bewustelike 'opskorting' van die interpreteerder se 'standaard' vooronderstellings oor die sosiale bestaan van mense (kyk Horsley [1989] 1994:69).

Die lewens van mense in eerste-eeuse Palestina het baie anders gelyk as dié van mense in 'n moderne, Westerse, geindustrialiseerde samelewing. Die leefwêreld van die Nuwe Testament was gevorm deur 'n pre-moderne landboukultuur. 'n Bepaalde ontwikkeling het reeds plaasgevind as gevolg van onder andere die gebruik van die ploeg, die munt van geld en die opkoms van groot politieke moondhede (kyk Stegemann \& Stegemann 1995:45-47; Lenski, Nolan \& Lenski 1995:175-222). Rykdom en mag is oneweredig verdeel en was in die hande van 'n klein groepie mense. Sosiale klasse is streng hiërargies georden. 'n Vrou het identiteit gehad slegs in relasie tot 'n manspersoon (haar vader of eggenoot, of substituut van vader of eggenoot). Om begrip te hê van die simboliese en sosiale universum van die mense waarvan die Bybel praat, is 'n sosio-historiese ondersoek noodsaaklik (kyk Horsley 1994:67). Betekenis word binne 'n sosiale sisteem bepaal (kyk Malina 1993:2). Dit is moontlik dat mense wat nie deel het aan dieselfde sosiale sisteem nie, verskillende dinge bedoel, al gebruik hulle dieselfde woorde. As betekenis verkry word in terme van 'n sosiale sisteem en woorde betekenisse binne daardie sosiale sisteem het, is dit noodsaaklik dat die woorde van die Bybel nie net semanties verstaan sal word nie. Dit is ook nodig om insig te hê in die sosiale sisteem van die Mediterreense wêreld, as 'n mens die Bybelskrywers en persone se woorde en dade waarvan die Bybel getuig, goed wil begryp. 


\section{PERSOONSKAP EN GROEPSIDENTITEIT}

Die belang van die individualiteit van 'n persoon was nie 'n sentrale waarde in die Palestynse samelewing gedurende die eerste eeu voor en na die Christelike jaartelling nie. Die geografiese term 'Palestina' word hier gebruik as aanduiding van die landstreke in die oos-Mediterreense gebied wat in hierdie tyd onder die militere bewind van die Romeine gestaan het. Dit sluit gebiede in soos Judea, die noordelike streek bekend as Samaria, Galilea, Siriè en die Dekapolis. Sedert die aanbreek van die moderne geìndustrialiseerde samelewing gedurende die sestiende tot die agtiende eeu na Christus het die klem vanaf groepsidentiteit verskuif na die waarde en regte van individue. Binne die eerste-eeuse Mediterreense wêreld is beide man en vrou egter nie beskou as outonome individue wat in die eerste plek ter wille van eie belange gefunksioneer het nie. In hierdie kultuur is elke individu gesien as ingebed in 'n groter geheel. Mense was groep-georiënteerde persoonlikhede en hulle menswees is ook deur die groep gedefinieer (vgl Malina 1996:44-49).

Die mees belangrike instelling in die Mediterreense samelewing was die familie. Alle persone, en dit geld veral vir vroue en kinders, was op sosiale, godsdienstige, ekonomiese en psigologiese vlak ingebed in die patriargale familie. Alle afsonderlike lede van die familie het bygedra by tot die beswil van die geheel (Malina \& Rohrbauch 1992:287). Binne so 'n raamwerk het 'n persoon se identiteit daarvan afgehang of hy of sy behoort tot en aanvaar was deur ' $n$ familie. Aanvaarding deur die familie het weer daarvan afgehang of die persoon die tradisionele reëls waarvolgens Mediterreense families georganiseer is, gehoorsaam het. Hierdie konvensies het grotendeels berus op die basiese waardes van eer en skande (Malina 1993:31-54). Die reëls was nie dieselfde vir mans en vroue nie. Die Mediterreense familie was patriargaal van aard (kyk o a Matthews \& Benjamin 1993:7-24). Die vader was die hoof van die familie. Ingebed by hom was sy vrou(e) en kinders. Selfs volwasse, getroude seuns het deel gebly van die vader se familiesisteem. Die oudste seun het sy vader opgevolg as hoof van die familie. Die vader het heelwat mag gehad oor die mense wat lede van sy familie was. Die ideaal in die samelewing was nie dat hierdie mag selfsugtig vir eiebelang aangewend sou word nie. Die patriarg was nie 'n onafhanklike manlike volwassene volgens die moderne patroon nie. Hy was as ' $t$ ware die beliggaming van die familie. Hy was die manlike hoof wat oor die familie regeer het. Sy hooftaak was om te sorg vir die beswil van die familie. Hy moes toesien dat die familie se rykdom in stand gehou word, dat die eer van die familie in die oê van die wêreld behou, en indien moontlik, vermeerder word, en om die familie na buite toe (ook in terme van die verhouding met God) te verteenwoordig. Ander lede van die familie was ondergeskik aan hom en moes hom behulpsaam wees in sy taak (Hanson 1996:76; Countryman 1988:150; Malina 1996:52). 


\section{GESLAG}

Die antieke Mediterreense samelewing het die wêreld in terme van geslag gesien.

Von hoher sozialer Bedeutung war ... die Zugehörigkeit einer Person zum männlichen bzw. weiblichen Geschlecht. Diese antike Einstellung ist damit ein Beispiel für die kulturanthropologische Einsicht, daB Geschlecht ein soziales Konstrukt ist bsw. sozial definiert wird, insofern die Rollenzuweisungen und Kompetenzverteilungen an die Geschlechter 'eigebettet' sind in die sozialen und kulturellen Rahmenbedingungen einer Gesellschaft.

(Stegemann \& Stegemann 1995:309)

Die skeiding tussen die geslagte is in hierdie wêreld gebruik as 'n basiese simbool waarvolgens die werklikheid as manlik en vroulik geïnterpreteer is. Hierdie geslagtelike siening van die werklikheid het deurgedring tot terreine soos familie, tyd, ruimte en die natuur (Malina 1996:49-51). Die plek, posisie, rolle en waarde van persone binne die familie was deur geslag bepaal. Mense was gedefinieer op grond van hulle geslag en geslagsrolle. Arbeid was verdeel op grond van geslag. Beweegruimte hoe vryelik 'n persoon mag beweeg en waarheen hy of sy mag beweeg - was bepaal op grond van geslag. Die geslag-georiënteerde familie het gedien as die basiese struktuur waarvolgens die hele Mediterreense samelewing georden was. Die skeiding op grond van geslag tussen manlike en vroulike rolle het een van die mees sentrale kulturele waardes in Palestina tydens die eerste eeu gevorm.

Die skeiding en ongelykheid tussen man en vrou, soos geskep en in stand gehou deur die tradisionele patriargale siening, word ook die grondliggende analogie waarvolgens die skeppingsorde verstaan word: God is ten opsigte van die man soos die man is ten opsigte van die vrou. Ook wat die natuur betref, staan die mens teenoor die natuur soos wat man staan teenoor vrou. Wat die baas vir sy slaaf is, is die man vir die vrou. Die keiser staan in verhouding tot sy onderdane soos wat die man in verhouding staan tot die vrou. Die leermeester is vir sy leerling soos die man vir die vrou (kyk JacobsMalina 1993:2). In die patriargale familie is die vader die verteenwoordiger van God, asook dié een wat moet verseker dat God gehoorsaam en gedien word. Om God se seën te kan ontvang, moet 'n mens tot 'n familie behoort, en binne die familie beskik die vader oor 'n God-gegewe status (Van Aarde 1997:456). Robert Hamerton-Kelly (1979:27) verwys soos volg na die vader as simbool van God se teenwoordigheid: 
The symbol of (God's) being and presence is the father in the family, who, in turn, is responsible for that family's worship and obedience to God. To share in God's blessing one had to belong to a family. Thus the status of the father was divinely sanctioned and the divine was involved in the history of the individual and society at the most intimate level, the level of the family.

In die totale sisteem was mans beskou as beter as vroue en dit alleenlik op grond van hulle geslag. Die status van die man het berus op die veronderstelling dat die manlike saad alles bevat wat nodig is vir sy nageslag. Die vrou verskaf in die reproduksieproses alleenlik die plek waar die saad moet groei, en voeding en versorging van die man se kinders ná die geboorte. 'Flowing from this interpretation of human reproduction was an ordering of society which gave the male a position superior to that of the female' (Jacobs-Malina 1993:1). Mans het die eer van die familie verteenwoordig, die familie se belange in die buite-wêreld behartig, alles besit en het as taak gehad om die eer van hulle vroue te beskerm. Vroue het dus die beskerming en sorg van mans nodig gehad, hulle taak in die binnekring van huis en familie gevind en moes sensitief wees vir die familiehoof se poging om sy eer te bewaar deur absoluut kuis te wees (Malina 1993:53). Dit alles kom daarop neer dat die totale lewe van vroue ingebed was in 'n raamwerk wat vir mans hulle eer en skande bepaal het. Die lewe van 'n vrou was deur die lewe van 'n man begrens.

In die samelewing van die eerste-eeuse Palestina was geslagsrolverskille duidelik gedefinieer en streng gehandhaaf (Malina 1996:51). 'n Man wat opgetree het soos 'n vrou, dit wil sê enigiets sou doen wat deel is van 'n vrou se rol, het dus die grens wat die heel strengste gehandhaaf was, oorskry. So 'n 'oortreding' het 'n man sy eer gekos (kyk Jacobs-Malina 1993:2). Tipiese vroue-gedrag was, in die geval van 'n arm kleinboerdery huishouding waar vrouens saam met die mans vir etes 'aangele' het, om die onbelangrikste (die laaste) plek aan tafel in te neem en om aan tafel te bedien. Ook tipies van die optrede van 'n vrou, maar nie van 'n man nie, was om ander se oortredings te vergewe, barmhartigheid te betoon en wonde te probeer genees (Malina 1993: 54).

\section{DOGTERS}

'n Kind het nie deel van die huishouding van 'n patriarg geword net omdat die kind binne die huishouding gebore is nie. Dit was eers wanneer die vader die kind amptelik aanvaar en aangeneem het, dat die kind beskou was as syne (Matthews \& Benjamin 
1993:10). Hierdie aanvaarding van die vader, eerder as die geboorte, het vir die kind die begin van lewe beteken. So gesien, het die vader dus die mag van lewe of dood oor die kind gehad. Die vader is vir die kind soos 'n 'goddelike wese' (Van Aarde 1997:459).

In Palestina in die eerste eeu was daar nie net verwys na kinders in die algemeen nie. Alle verwysings na kinders was geslagspesifiek: seuns of dogters. Die geslag van 'n kind het ook bepaal hoe die aankondiging van die geboorte sou verloop. Seuns was baie meer belangrik as dogters. Daar word byvoorbeeld geen geboorte-aankondigings van dogters in die Nuwe Testament aangetref nie. God praat hoogstens met vroue in die konteks van prokreasie (vgl Moxnes 1996:32-33). Nog 'n aanduiding van die mindere waarde van 'n dogter is dat, volgens Levitikus 12 , die tydperk van reiniging wat 'n vrou deurgaan nadat sy geboorte geskenk het, twee maal so lank is as sy 'n dogter in die wêreld gebring het as wanneer dit 'n seun was (Countryman 1988:29). Dit is duidelik dat dogters minder 'waardevol' as seuns vir 'n familie was. Dogters kon nie help met die opbou van die eie familie nie, maar wel met dié van hulle man. Die voordeel van dogters was dat hulle uitgegee kon word in huweliksverbintenisse wat ekonomies en polities voordelig vir die pa en sy familie kon wees. Op dié manier het die dogters se eie familie invloed en politieke sekuriteit verkry. Vir hierdie doel was dit noodsaaklik dat die dogter 'n maagd moes wees, anders was sy nie geskik vir 'n huwelik nie (Countryman 1988:158). Daarom het die familie tydens die eerste huweliksnag gewag vir 'n seremoniële teken dat die bruid 'n maagd was, want indien dit nie die geval was nie, kon die bruidegom haar verlaat, met die gevolg dat bruid se familie beskaam is en haar pa sy bruidskat verloor het.

Dogters is slegs deur vroue grootgemaak. 'n Dogter het geen kinderlewe gehad nie. Sodra sy daartoe in staat was, is sy huishoudelike rolle en pligte geleer. Die take was dikwels moeilik en fisiek veeleisend. Van die begin af was dogters geleer dat die openbare lewe gereserveer is vir mans en dat hulle daarvan uitgesluit was. Jong seuns, aan die ander kant, is op die hande gedra, hoewel die pa ook hier vir die eerste aantal jare geen rol gespeel het in die grootmaak van seuns nie. Hulle was twee maal so lank as dogters geborsvoed en het van vroeg af ervaar dat vroue flink reageer om aan hulle wense en eise te voldoen. Anders as by seuns het die vader geen rol in die opvoeding van dogters gespeel nie. Daar was 'n groot afstand tussen vader en dogter en die verhouding was dikwels redelik hard en ongenaakbaar. Die vader se grootste bekommernis was dat 'n dogter skande oor hom en sy familie sal bring. Dit kon gebeur as sy nie getroud gekom het nie, as sy verkrag sou word, as sy ontrou aan haar eggenoot sou wees, of as sy swanger sou word voor haar huwelik (Malina \& Rohrbauch 1992:300). In 'n Engelse vertaling van die Wysheid van Jesus ben Sirag (42:9-11) word hierdie bekommernis soos volg verwoord (in Malina 1993:128): 
A daughter keeps her father secretly wakeful, and worry over her robs him of sleep; when she is young, lest she do not marry, or if married, lest she be hated; while a virgin, lest she be defiled or become pregnant in her father's house; or having a husband, lest she prove unfaithful, or, though married, lest she be barren.

Keep strict watch over a headstrong daughter, lest she make you a laughingstock to your enemies, a byword in the city and notorious among the people, and put you to shame before the great multitude.

Die hoofdoel van 'n dogter was om so op te tree dat sy die waardes en belange en eer van haar vader se familie bevorder het. Die dogter moes ook haar vader se gesag or haar erken, want dit was algemeen beskou as sy God-gegewe plek in die statushiërargie. Die vader het dus absolute gesag en sosiale beheer oor sy dogter gehad (Malina 1993:5).

Huwelike was in die algemeen deur die pa's van die twee onderskeie families gereël. Omdat die dogter ingebed was in sy familie, was dit die vader se plig en reg om te besluit met wie sy dogter gaan trou. Sy was dus nie 'n individu wat vry was om self te besluit nie. Sy sou altyd beskou word as verbonde aan haar vader en sy familie. Die huwelik in die ou Midde-Ooste was dus meer die samevoeging van twee families as die bymekaarwees van twee individue. Die onderskeie pa's moes sorg dat die families op dieselfde sosiale vlak was en dat die een familie nie sal voordeel trek bo die ander nie. Die huwelikskontrak het intensiewe onderhandelings geverg om seker te maak dat daar voldoen word aan al die sosiale reëls. Aangesien 'n huwelik 'n politieke, ekonomiese, godsdienstige en huishoudelike aangeleentheid was, het families dikwels 'n kontrak gesluit lank voordat die kinders hubare leeftyd bereik het. Dit het dan 'n langtermyn verlowing beteken (Malina \& Rohrbauch 1992:289). Dit is dus duidelik dat wat die moderne Westerling onder die begrip 'verlowing' verstaan, ver verwyderd is van wat dit was in die antieke Mediterreense wêreld.

\section{DIE PERSONALITEIT VAN DIE VROU}

In die literatuur van die vroee Jodedom vind ons 'n redelike donker prentjie van die vrou. Waar daar wel positief gepraat word oor vroue, is dit slegs in die konteks van die huwelik en moederskap. Solank die vrou haar aan die ondergeskikte rolle en die 
reèls daaraan verbonde, onderwerp het, is sy in die geskrifte van mans geprys anders nie. Die beeld van die vrou as persoon, as entiteit op haar eie, is slegs negatief geskilder. So 'n vrou is byvoorbeeld gesien as gevaarlik, boos en 'n seksuele verleidster. Dit alles lê in haar natuur. Die man moes homself altyd beskerm teen haar verleidelikheid. Sulke uitsprake word ryklik gevind in die Wysheid van Jesus ben Sirag, die werke van Filo van Aleksandriè en van Josefus (kyk Van der Horst 1993:77).

Max Küchler het in sy boek, Schweigen, Schmuck und Schleier (aangehaal deur Van der Horst 1993:81), aangedui dat daar in die vroeg-Joodse geskrifte 'n dubbele proses aan die werk is: die erotisering van die vrou en die demonisering van die erotiese. Volgens hom lei hierdie proses daartoe dat daar in die cerste eeue na Christus 'n openlike vyandigheid teenoor die vrou te sien is in verskeie pseudepigrafiese en Rabbynse geskrifte. Hierdie geskrifte vertoon weer die gemeenskaplike wêreld in terme waarvan Nuwe-Testamentiese tekste soos 1 Korintiërs 11:10 en 1 Timoteus 2:8-15 gekommunikeer het. Hierdie twee tekste verwys onderskeidelik na die dra van 'n sluier as teken van vroue se erkenning van die man se gesag, en na vroue wat 'God dien'. Hulle diens aan God word sigbaar in hulle beskeie en ingetoe voorkoms en gedrag. Dit dui op hulle onderdanigheid aan die man. Sommige tekste verwys weer na die vrou se 'boosheid' waarvan sy verlos sal word deur moeder (van 'n seun) te word. Die aanname van die vrou se 'boosheid' (wat teruggevoer word na Eva se paradysgeskiedenis) legitimeer die ondergeskiktheid van die vrou aan die man. Die vrou wat in beginsel so gevaarlik is, kan geen toegang kry tot middele, mag en geleerdheid nie. Ook hierdie tema kom in vele geskrifte voor (kyk Van der Horst 1993:81).

'n Vrou wat nie ingebed is by 'n man (vader of eggenoot) nie, soos byvoorbeeld die weduwee of geskeide vrou, word gesien as 'n vrou sonder vroulike eer. Sy is dus meer soos 'n man as soos vroue, en derhalwe gevaarlik. Slegs 'n volgende huwelik kan haar herstel tot haar kultureel-bepaalde geslagsrol. In daardie samelewing is dit egter nie altyd moontlik om weer getroud te kom nie. Die familie van 'n hubare man soek na 'n maagd vir hulle seun. Dit verklaar dus waarom weduwees en geskeide vroue se posisie in daardie kultuur so onbenydenswaardig was (Malina 1993:44). Dubbele maatstawwe kan gesien word in die feit dat daar in die samelewing 'n blinde oog gekeer is op 'n praktyk waar daar soms van enkellopende weduwees verwag is om adolessente seuns in die 'seksuele praktyk' in te lei.

Die Hebreeuse woord vir 'weduwee' (almanah) dui op iemand wat stil is, wat nie kan paat nie. In 'n samelewing waar slegs manlike persone in die openbare lewe funksioneer en ' $n$ vrou nie in haar eie belang mag praat nie, is die weduwee ' $n$ besonder weerlose persoon. Aangesien vroue ook nog deur die wet uitgesluit word van die moontlikheid om te erf, word die weduwee in daardie kultuur die stereotipiese simbool 
van iemand wat uitgebuit en onderdruk word. Weduwees en weeskinders wat nie aan 'n patriarg verbonde is nie, is gemarginaliseerde mense wie se belange baie maklik vertrap kan word (Countryman 1988:150; Malina \& Rohrbauch 1992:397).

Returning to the definition of almanah, we note that such a woman has not only lost her husband, but she is a woman who has no male from the kin group of her dead husband who can take responsibility for her. She has no brothers-in-law or sons. In fact, she has no male kin from her dead husband's group. In that patriarchal society, she is a woman who is destitute because she has no male guardian. The implications of such a situation are staggering: she is a woman whose sexuality is not controlled by a male; her dead husband has no surviving kinsman to guard his honor; her dead husband's property is in jeopardy, and most important, his name and his line will cease.

(Rook 1998:5)

\section{EER EN SKANDE}

\section{1 'n Kulturele sleutelwaarde}

In die Mediterreense sosiale wêreld het eer en skande as sentrale waardes binne 'n familiale opset gefunksioneer. In die moderne, Westerse, geindustrialiseerde kultuur neem ekonomiese belange hierdie sentrale plek in. Binne die Mediterreense kultuur is eer sowel 'n persoon se gevoel van eiewaarde as die openbare erkenning van daardie waarde. In hierdie sin besit beide mans en vroue eer. Dit gaan oor 'n persoon se reputasie en sosiale stand, ongeag die persoon se geslag. In hierdie konteks is skande 'n positiewe simbool. Dit dui op die persoon se gevoeligheid vir sy of haar reputasie en die opinie van ander. 'A sense of shame makes the contest of living possible, dignified, and human, since it implies acceptance of and respect for the rules of human interaction' (Malina 1993:51).

Binne die leefwêreld van die Bybel waar die reputasie van mans en vroue se gemeenskaplike mensheid of gemeenskaplike belange, soos die van die familie, die dorp of stad op die spel is, is daar sprake van eer vir sowel mans as vroue. In die gevalle binne die Mediterreense konteks waar eer die prerogatief was van slegs een geslag, het eer tot die sfeer van die man behoort en skande tot dié van die vrou. As dit kom by 
konkrete individuele gedrag (los van groepsbelange) was eer en skande spesifiek tot geslag. Dit beteken dat 'n manlike individu eer simboliseer en 'n vroulike individu skande. 'Unlike the male whose gender made him whole and complete, the female was raised with a sense of shame which made her as dependent on the male for her own "completeness" as she was dependent on him for children, support and honor' (JacobsMalina 1993:1).

Manlike eer was gesimboliseer in sy testikels. Die waardes en gedrag wat met manlike eer gepaard gegaan het, was manlikheid, moed, gesag, bekerming van die familie se eer, besorgdheid oor prestige en sosiale onafhanklikheid. Vroulike skande was gesimboliseer in haar maagdevlies. Die waardes en gedrag wat met die vrou se skande te doen het, was skaamheid, om nie naak gesien te word nie, om te bloos, skugterheid, terughoudendheid en seksuele eksklusiwiteit. Al hierdie dinge konstitueer positiewe skande vir 'n vrou en maak haar eerbaar (Malina 1993:50-51). Die verskil tussen die positiewe en negatiewe aspekte van skande is dat skaamheid die besorgdheid oor jou eer is, terwyl beskaming die verlies van eer veronderstel.

Omdat eer een van die mees sentrale waardes in die antieke Mediterreense wêreld verteenwoordig, hou dit verband met al die vlakke van die samelewing. Die instandhouding, beskerming, verlies en herstel van eer wat mans toekom, vorm dus die matriks van waanuit sosiale waardes en gebruike voortkom. Hierdie sosiale waardes en gebruike bepaal weer op hulle beurt die gedrag van albei die geslagte (Jacobs-Malina 1993:1, 2).

\subsection{Die getroude vrou}

Die ideale stand van sake vir ' $n$ volwasse vrou in die antieke Mediterreense samelewing was om in die huwelik te tree. Die samelewing het van die vrou verwag dat haar hele lewe en persoonlikheid sou opgaan in die private sfeer van 'n man se huishouding. Eers het sy tot die huishouding van haar vader behoort, en daarna tot dié van haar eggenoot (Jacobs-Malina 1993:2). Ek het reeds daarop gewys dat die huwelikskontrak deur die familiehoofde onderhandel was - met politieke, ekonomiese en sosiale belange as die fokuspunt. Vir die verlies van 'n lid van die familie deur 'n huwelik, moes die pa van die bruid gekompenseer word in die vorm van 'n bruidsprys (Malina \& Rohrbauch 1992:290). Die man se ouers moes in gedagte hou dat van die nuwe vrou verwag is om in te pas in 'n gevestigde familie waar 'n hele aantal persone daardeur geraak sou word. Die ouers van die vrou het weer 'n man van goeie status in die samelewing, wat 'n goeie voorsiener en vader sou wees, vir die dogter gesoek.

Die bruid het nie van haar man kameraadskap of ondersteuning verwag nie. Dit het sy van haar broers en susters of van ander vroue binne die huishouding gekry. Die 
Mediterreense samelewing was so gestruktureer dat mans en vroue in totaal verskillende kringe beweeg het. Daar mag hier en daar raakpunte wees, maar dit kom nooit coreen nie: 'n Te groot mate van spontane liefde sou 'n negatiewe effek kon hê op die regte en die belange van die sisteem as geheel. 'This need to limit spontaneous affection ... is a basic feature of those arranged marriages found in kinship systems where the newly married couple is incorporated into a larger kin group' (Malina 1993:124).

In 'n samelewing, soos in die tradisionele Mediterreense wêreld, waar die klem gelê het op die vriendskapsbande tussen mans en op die regte van mans, is die nuwe vrou nooit werklik geintegreer in die familie van haar man nie. Teen puberteit was sy oorgeplaas vanaf die huishouding van haar vader na die huishouding van haar man. Sedertdien was sy nooit werklik 'n volle lid van een van die twee huishoudings nie. Vir die grootste gedeelte van haar lewe het sy op die periferie van haar man se familie beweeg. Sy is behandel soos ' $n$ vreemdeling in die huis, want die huwelik as sodanig was nie beskou as 'n bloedverwantskap nie. Die vrou kon weer uit die familie uittree wanneer haar man besluit het om van haar te skei. Net die man het oor die reg om te skei beskik (Countryman 1988:151, 152; Malina \& Rohrbauch 1992:29). Die vrou se enigste beskerming in die huwelik was as haar man dit polities, ekonomies en sosiaal gesproke dit onverstandig sou reken om haar vader se eer aan te tas deur van haar te skei (Countryman 1988:155). Die mag wat die patriarg sowel as haar eggenoot oor haar gehad het, het beteken dat 'n vrou slegs 'n sekondêre plek ingeneem het in die huishouding waarin sy haar bevind het. Hierdie ondergeskikte status word onderskryf deur die reg wat haar eie vader of haar man gehad het om selfs haar beloftes aan God nietig te verklaar (Countryman 1988:152).

Die taak van die getroude vrou was om die familie van haar man te dien deur kinders te baar en groot te maak (sosialiseer), voedsel te verwerk, klere te maak en die huishouding effektief te administreer (kyk Matthews \& Benjamin 1993:25-27). Die hoofdoel was dus nie die persoonlike bevrediging van haar man nie, maar die opbou van sy familie. Die vrou was uiters aktief en het van die môre tot die aand gewerk. Indien daar 'n huishoudelike probleem ontstaan het, was daar van die vrou verwag om iets daaraan te doen, terwyl die man sit en die probleem bedink het (Jacobs-Malina 1993:2). Die ideale vrou/moeder in die tradisionele, patriargale huishouding het status verkry deur haarself totaal te gee in diens van dié bokant en onderkant haar in die sosiale hiërargie (Jacobs-Malina 1993:4).

Die vrou kon die rol van vreemdeling in haar man se familie in ' $n$ mate afskud as sy 'n seun in die wêreld gebring het. Die geboorte van 'n seun het vir haar sekuriteit, status en erkenning in haar man se familie verseker. Eers dan het haar huwelik 'n bloedverwantskap meegebring waarop sy kon staatmaak (Malina \& Rohrbauch 1992: 
242, 287). Haar verhouding met haar seun(s) het weer 'n reeks ander sosiale implikasies gehad. Dit het veroorsaak dat 'n getroude, volwasse vrou 'afhanklik' van haar seuns geword het - nie net vir aanvaarding deur haar skoonfamilie nie, maar ook vir sosiale status in die bree samelewing. Vroue was daarom baie beskermend ten opsigte van hulle seuns. Sonder 'n seun het 'n vrou geen kans op erkenning van haar persoonskap nie en as haar man sou sterf, en daar nie nie 'n ander manlike subsitituut in haar man se familie was nie, het sy 'n almanah (weduwee) geword.

Op grond van 'n saak soos hierdie is ek krities ingestel wanneer Ou-Testamentici soos Victor Matthews en Don Benjamin die Mediterreense patriargale samelewing teenoor feministiese teoloë wil verdedig:

The status of women in early Israel may be no model for the reconstruction of contemporary society on more inclusive principles, but neither is it a unilateral endorsement for the subordination of women. And the world of the Bible may not be feminist, but neither is it completely male oriented. It may not be liberated, but it is liberating. The world of the Bible was a 'patriarchy.' The word refers to a particular kind of social system. Theoretically at least, patriarchy is not sexism, which is a form of prejudice and oppression based on the faulty assumption that women are biologically inferior to men ... Sexism misuses power to deprive women of autonomy ... It exists in societies of all kinds, but not because they are patriarchal ... There are a variety of patriarchal societies, but they all have two characteristics in common. They are all 'patrilocal,' which means that a woman lives in the household of her husband. And they are all 'patrilinear,' which means that the heir of the household must be a natural or adopted son of the father.

(Matthews \& Benjamin 1993:22-23)

Die probleem met die sogenaamde 'bevrydende' plek en rol van die vrou in 'n patriargale samelewing, soos dit in onder andere die aanhaling hierbo gestel is, is dat haar inbedding en binding aan die plek en rol van die man, onaanvaarbare sosio-religieuse gevolge gehad het. In 'n samelewing wat die heil en die welsyn van die mens nie van mekaar geskei het nie, het die verlies aan eie identiteit ook 'n vryheidlose bestaan voor God meegebring. Binne die patriargale sisteem is die vrou nie 'n plek vorr God, selfstandig en los van die man, gegun nie. Kan só 'n vryheidlose lewe as outentieke bestaan gesien word? Net soos mans volgens Nuwe-Testamentiese getuienis bevry moes 
word van hulle afhanklikheid van 'n priester en die konvensies wat dit reguleer het, sodat hulle God se direkte en onbemiddelde teenwoordigheid kon ervaar, vereis die evangelie die vrou se vryheid van manlike, patriargale dominansie. Die soteriologiese beginsel in die twee gevalle, by man en vrou, verskil tog nie! Die feit dat slegs seuns kon erf, het eweneens gevolge gehad vir die aanwending van simbole wat die saak uitdruk dat mense (mans allénn) die koninkryk van God kan beèrwe.

Die feit dat ' $n$ volwasse vrou binne die patriargale sisteem afhanklik van selfs haar eie seun gemaak word, is myns insiens, uit 'n sosiologiese hoek gesien, onaanvaarbaar. Selfs die prestasies van ' $n$ seun is in só samelewing beskou as 'n refleksie op die waarde van die moeder (kyk Malina 1990:54-64). In 'n kultuur met sulke waardes is dit te verstane dat die posisie van 'n onvrugbare vrou of 'n vrou wie se man onvrugbaar is ('n moontlikheid waaroor daar in die kultuur nie eens gedink is nie) uiters ellendig. Verhale van sulke vroue, waarvan daar 'n paar in die Bybel voorkom, verwoord die diepste sielewroeging (Malina \& Rohrbauch 1992:287). 'There was no greater sorrow for an Israelite or Oriental woman than childlessness. Even today among the Arabs the barren woman is exposed to disgrace and even grievous wrongs. These views, which derive from the human code of honor, and the customs to which they give birth also play a role in the patriarchal stories' (Von Rad 1972:191). Hoewel die vrou in die antieke Mediterreense kultuur nooit werklik volledig lid van haar man se familie geword het nie, was sy wel haar man se besitting en daarmee saam ook die familie se besit. Vandaar dus die wet op die leviraatshuwelik (Countryman 1988:155).

Die opvatting dat slegs die man kinders genereer, kan onder andere in die geslagsregisters in die Nuwe Testament gesien word. Hierdie geboorterekords is patriliniêr georden. Dit getuig van die man se status as die draer van regte in die gemeenskap. Met die gebrek aan biologiese kennis in die tyd, was daar gemeen dat die wese van die pasgebore seun of dogter geneties direk en uitsluitlik van die vader kom. Die moeder dien net as 'n passiewe voedingsbron wat die fetus dra en in die kind in die wêreld bring (Malina \& Rohrbauch 1992:25). Die verwysing in Eksodus 38:8 na 'vroue wat by die deur van die tent van ontmoeting werk' is in hierdie verband nie so onskuldig nie. Dit het betrekking op vroue wat of swanger was of gemenstrueer het en nie toegelaat was om take as gevolg van onreinheid binne 'n huis te verrig nie, maar wel om buite die deur van die huis (of van die kultiese ruimte) werk te doen (vgl Matthews \& Benjamin 1993:30). Binne huishoudings waar die patriarg meer as een vrou gehad het, moes die vrou wat die mees senior posisie beklee het, toesien dat die ander vroue gereeld swanger raak en kinders in die lewe bring.

Anders as by die omliggende volke was Israelitiese vrouens nie toegelaat om priesters te wees nie. In die godsdienspraktyke van oud-Kanaāan en Mesopotamië het pel- 
grims by kultusplekke seks met vroue-priesters gehad en die patriarg se seksuele gemeenskap met so 'n priester was gesien as 'n gebed dat sy eie vrouens en sy eie stukkie grond vrugbaar sou wees (kyk Hooks 1985:65-151). '(E)arly Israel needed every available woman to bear children, and since women priests did not bear children, Hebrew women did not become priests' (Matthews \& Bejamin 1993:30). Hierdie verskynsel van vrouens in diens van die kultus het ook met die ekonomie verband gehou. Net soos 'n verwagte surplus in die ekonomie aan koninklikes en hulle priesterlike ondersteunersklas afgestaan moes word, so ook die 'surplus' vroue wat kinderloos was (vgl bv die 'verhaal' agter die verhaal van die kinderlose Hanna in die tempel in Silo wat diep uit haar hart God gesmeek het om vir haar ' $n$ seun te gee - 1 Sam 1:1-2:11).

\subsection{Die slavin}

Net soos die bestaan van vroue-priesters ingebed was in 'n surplus ekonomie binne die Mediterreense sosiale wêreld, was dit ook die geval met slavinne wat deur patriarge besit was. Hierdie vroue is deur onderdanige (moontlik militêr corwonne) familiehoofde aan 'n heersende patriarg geskenk soos wat die surplus koring as belastingverpligting oorbetaal was (vgl Meyers 1978:98; Matthews \& Benjamin 1993:30).

Die ideaal vir ' $n$ vrou in die antieke Mediterreense kultuur was om te trou. Hoewel haar posisie in die huwelik sekondêr was, kon om nie te trou nie, selfs 'n nog slegter posisie tot gevolg hê. 'n Groot aantal vroue in dié kultuur het hulle in verskillende vorme en grade van slawerny bevind. Selfs die vrou wat die status van eggenote "behaal' het, kon dit verloor deurdat haar man van haar skei of sy 'n weduwee word. Die slavin was nie net ondergeskik aan die patriarg nie, maar aan die hele familie-hiërargie, insluitend die patriarg se vrou. Indien die slavin getroud was met 'n slawe-man, ontstaan die probleem van eienaarskap. Aangesien die verhouding van 'n man tot sy vrou gelykstaande is aan die van ' $n$ baas tot sy slaaf, is die vraag: wie is die eintlike eienaar van die vrou - haar man, of die familiehoof? Eksodus 21:3-6 beslis die saak op grond van wie die eerste eienaar was (Countryman 1988:154).

\subsection{Die prostituut}

In die eer-en-skande kultuur is dit selfs vir mense moontlik om hulle skaamte totaal te verloor. '[Natural] groups can lose their shame by getting shamed to such an extent that they no longer have shame but are shameless' (Malina 1993:53). Prostitute was beskou as permanent sonder enige eer. Die rede daarvoor is dat hulle die grense van eksklusiwiteit nie respekteer nie en daarom simbool word van chaos. Mans wat prostitute besoek, is egter nie deur die samelewing veroordeel nie (Countryman 1988:38). 
Die samelewing het prostitusie egter wel vaagweg afgekeur. Die rede daarvoor was die opvatting dat die man sy saad verkwis in plaas van om dit te bestee aan die opbou van sy familie. So 'n verkwisting getuig daarvan dat individuele belange voorrang bo die beginsel van ondergeskiktheid aan die belange van die familie geniet. In 'n kultuur wat waarde aan kollektiwiteit in plaas van individualiteit heg, is sulke selfsug onaanvaarbaar (Countryman 1988:167).

\subsection{Die byvrou}

'n Man kon 'n vrou in sy huishouding inneem as byvrou. Hierdie praktyk was moontlik 'n geleentheid vir 'n jongman om 'n eerste seksuele maat te verkry, sonder om die verpligting te hê dat haar (sic!) kinders as sy erfgename aanvaar hoef te word (kyk Countryman 1988:155). 'n Ander voordeel vir 'n man om 'n byvrou 'aan te hou', was dat hy nie 'n bruidskat aan haar familie hoef te betaal het nie. Die sosiale posisie van die byvrou kom duidelik na vore in die verhaal oor die Leviet en sy byvrou in Rigters 19. Die vrou word nooit by die naam genoem nie. Haar wense word nie in ag geneem nie. Uiteindelik red haar man homself deur haar oor te gee in die hande van 'n wrede groep mans wat haar verkrag en vermoor (Countryman 1988:155).

\section{EGSKEIDING EN EGBREUK}

Die familiestruktuur in ou Israel het op geen manier gelykheid tussen man en vrou, of 'n totale eenheid tussen die getroude man en vrou erken nie. Die vrou, as besitting van die man, was wel op 'n manier sy verlengstuk. Sy was ook belangrik vir sy huishouding. Sy reg om van haar te skei, was uitdrukking van albei hierdie werklikhede. Hy kon van haar ontslae raak soos 'n mens van 'n slaaf kon ontslae raak. Aan die ander kant, moes hy haar hoër status (in vergelyking met dié van 'n slaaf) respekteer deur 'n rede vir die egskeiding aan te gee. Hy moes iets 'onbetaamliks' aan haar vind, soos byvoorbeeld dat sy nie 'n maagd was nie, of nie haar maagdelikheid ken bewys nie (Countryman 1988:174, 175). Dan kon hy haar gewoon wegstuur met 'n skeibrief. Hy het nie verder 'n verantwoordelikheid ten opsigte van haar of wat van haar word, gehad nie.

Die vrou wat op hierdie manier weggestuur is, het net een eerbare opsie, en dit is om terug te keer na haar vader toe as die vader haar kon en wou terugneem. Die ideale sou wees om weer te trou, maar aangesien sy nie meer 'n maagd was nie, het sy nie juis waarde in die huweliksmark gehad nie. Indien haar vader haar nie teruggeneem het nie, het daar geen eerbare manier vir ' $n$ vrou bestaan om haarself te onderhou nie. Sy was dan verplig om oor te gaan tot moontlikhede waar sy haar kuisheid (skaamte) totaal verloor het, soos om haarself as slaaf te verkoop of om 'n prostituut te word. So 
kon sy dan ten minste aan die lewe bly. Die vooruitsigte vir 'n vrou wat deur middel van egskeiding weggestuur was, was in die antieke Mediterreense kultuur besonder donker.

In die Joodse wet van die tyd het egbreuk daarop neergekom dat 'n man seksuele gemeenskap met die vrou van 'n ander man (getroud of verloof) gehad het. Die man pleeg dus nie egbreuk teen sy eie huwelik nie, maar wel teen die huwelik van die vrou en haar man. Dit was 'n oortreding van die reinheidsbeginsel dat 'n vrou eksklusief gebind is aan een man (Countryman 1988:35-37). Egbreuk was 'n ortreding van die besitreg van die man. Dit het dus neergekom op diefstal van 'n ander man se besitting (Countryman 1988:149). Die voortbestaan van die familie was afhanklik daarvan dat wettige erfgename verkry word. Die man was baie gesteld daarop dat die kinders sy wettige erfgename moes wees en dat sy familie se bloedlyn suiwer moes wees. As 'n buitestander gemeenskap sou gehad het met 'n getroude vrou, het hy haar man van sy reg op wettige erfgename beroof. Net soos die verlies van enige vorm van besit, was die man en die familie se eer hierdeur aangetas, en hulle status in die samelewing het dienooreenkomstig verminder (Countryman 1988:157). Egbreuk het dus beteken dat die eer van 'n man aangetas is as gevolg daarvan dat 'n ander man seksuele verhouding gehad het met 'n vrou wat in hom ingebed is. Dit kon sy vrou, ongetroude dogters en gaste insluit (vgl Malina 1993:137).

\section{BESITREG}

Omdat individualteit binne die patriargale sisteem nie na waarde geag was nie, was mense nie gesien as individue wat die moontlikheid het om as individue besittings te hê nie. Om te besit, was die alleenreg van die familiehoof. Die patriarg het nie net grond, diere en goedere besit nie, maar ook mense. Hy kon mans, vroue en kinders as slawe koop en besit. Sy eie vrou(e) en kinders was ook 'n vorm van besit. "Property" denotes something which is understood as an extension of the self, so that a violation of my property is a violation of my personhood' (Countryman (1988:147). Ons het reeds gesien dat, omdat die vrou as 'n vorm van besit beskou is, egbreuk gesien is as 'n aantasting van daardie besit, wat vergeld moes word met 'n aantasting van die cortreder se persoon. Wat vir vroue gegeld het, was ook op kinders van toepassing. In 'n kultuur waar vroue, kinders en slawe die besit was van die manlike familiehoof, was die verhoudings tussen die verskillende mense in die huishouding georden in die vorm van 'n hiërargiese struktuur. Hiërargie kan ook gesien word as uitdrukking van hierdie 'property relations' (Countryman 1988:152, 153).

Die vrou as besitting kon dus nie self iets besit nie (vgl egter Stegemann \& Stegemann 1995:320-321). 'n Uitsondering wat ons wel 'n enkele keer in die Bybel 
teenkom, is wanneer 'n vrou wel 'n erfgenaam word. Volgens die Tora kon dit net gebeur as daar geen seuns was nie (vgl Num 27:1-11). Sulke vroue was egter 'n verleentheid in die erfregsisteem. As hulle wel seuns gehad het, het die seuns alles geërf. Maar die seuns was nooit as deel van die vrou se familie gereken nie. Hulle was altyd beskou as deel van die man se familie. Op dié manier is dit weer 'n ander familie, en nie haar eie nie, wat na haar dood die eienaars van haar besittings geword het.

Die beeld wat die Ou Testament van die plek van die vrou in die familiesisteem bied, het oor 'n baie lang tydperk stabiel gebly, tot in die Nuwe-Testamentiese tyd. In die Nuwe Testament is wel geringe veranderings te bespeur, soos dat poligamie nie meer voorgekom het nie en dat die huwelikskontrak soms aan vroue die reg gegee het om van hulle mans te skei. Vroue het egter 'n spesifieke soort besit gebly en hulle funksie was om erfgename voort te bring en om te help met die huishouding van die man se familie (Countryman 1988:156).

Hierdie 'besitreg-etiek' was in die leefwêreld van beide die Ou en Nuwe Testament beskerm deur reëls en wette. Egbreuk is as verkeerd beskou, omdat dit diefstal van iemand anders se besit behels het. Bloedskande was verkeerd omdat dit opstand van die jonger geslag teen die ouer en oortreding teen die familie-hiërargie behels het (die presiese teenoorgestelde as die moderne Westerse siening van bloedskande). Prostitusie is nie in ' $n$ baie ernstige lig beskou nie, maar was tog verkeerd omdat dit aan individuele bevrediging voorrang gee bó die beginsel van ondergeskiktheid aan die familie.

\section{WAAROP DIT AANKOM - 'N REINHEIDSIDEOLOGIE}

Godsdiens, politiek, ekonomie en sosiale interaksie is in die Mediterreense kultuur gesien as 'n eenheid. Dit kom tot uitdrukking in die familielewe en plaaslike gemeenskappe, asook in die oorheersing deur sekere groepe (Countryman 1988:21; Horsley 1994:69). In elke samelewing is daar aspekte wat sin gee aan menslike bestaan. Dit word betekenissisteme genoem. Die mens word gebore binne sisteme wat grense bepaal en menslike ervaring definieer. Die mens grens nie alleen af en definieer nie, maar belê ook gevoelens in en ken waarde toe aan wat so afgegrens is. Dit kan wees persone, dinge, plekke en gebeurtenisse (Malina 1993:149-152).

Een manier om so 'n sosiale betekenissisteem te benoem, is deur middel van 'n reinheidsisteem. Wanneer die betekenisgewende sisteem bepaal dat iets nie inpas in die konvensionele plek nie, word daardie saak beskou as verkeerd, afwykend of sinneloos. Dit is ' $n$ onderskeiding tussen wat rein (in pas met konvensie) en onrein (uit pas met konvensie) is. Rein en onrein kan dan betrekking hê op persone, groepe, dinge, tye en plekke. Die onderskeid wat gemaak word tussen rein en onrein, verskaf die sentrale waardes van 'n samelewing. Op dié manier is al die lede van die samelewing seker van 
die betekenis en waarde van dinge, van wat gedoen mag word en wat aanvaarbare sosiale optrede is (Malina \& Rohrbauch 1992:318, 319). 'Purity systems thus provide "maps" designating social space and time in which everything and everybody either fits and is considered clean or does not and is regarded as defiled. These socially contrived maps provide boundaries marking off the places and times where things and people belong' (Malina \& Rohrbauch 1992:319). Elke kultuur het 'n 'reinheidsisteem', hoewel nie altyd so eksplisiet en uitgebreid soos die reinheidsisteem wat ons in die Ou en Nuwe Testament aantref nie (Countryman (1988:12). Alles wat vir die sosiale sisteem onbekend, onaanvaarbaar, onreëlmatig of ongesond is, is die sake wat as onrein geklassifiseer word (Countryman 1988:12, 13; Malina 1993:153).

Aangesien godsdiens in die leefwêreld van die Bybel nie geskei was van die res van die menslike bestaan nie, was die onderskeid tussen rein en onrein in die Bybel dus nie net 'n godsdienstige aangeleentheid en die wassingsrituele nie net godsdienstige rituele nie. Die reinheidsisteem het die totale sosiale opset op alle vlakke van menslike interaksie bepaal. In hierdie kultuur het reinheid te doen met die konsep 'heelheid': van elke individu is verwag om 'n volledige een van sy of haar soort te wees. Soorte mag ook nie vermeng gewees het nie. Daar is dus van afgrensing sprake. Die grense van die liggaam is baie belangrik in hierdie sisteem. Daarom is sake soos kos wat die liggaam binnegaan en stowwe wat uit die liggaam uitkom, in so 'n reinheidsisteem nie onbelangrik nie. Dinge wat uit die liggaam uitgaan, raak aspekte soos ekskrement, urine, bloed, moedersmelk, semen en vaginale afskeiding. Dit bring mee dat seksuele dade, dood, geboorte, herkoms en etnisiteit binne die Joodse reinheidsideologie skerp in fokus gekom het. Die reinheidswette het ten doel gehad om grense te stel, byvoorbeeld tussen Jode en ander volke (Countryman 1988:26, 64).

Omdat die mens nie oor God kan praat op 'n ander wyse as in vergelyking met die menslike ervaring nie, word God beskryf in terme van wat vir die samelewing belangrik is. In die leefwêreld van die Bybel is God dus gesien as heilig, volmaak, totaal, heel. Die algemene siening van die samelewing in dié tyd was dat voorspoed die gevolg is van gehoorsaamheid aan die reinheidsisteem en teëspoed die gevolg van ongehoorsaamheid (Malina 1993:158). Enige afwyking van heelheid, die normale staat van 'n persoon, het beteken dat so 'n persoon beskou is as onrein. S6 'n persoon het dan iets verloor en was nie meer soos wat hy of sy behoort te wees nie. Onrein mense het volgens hierdie ideologie nie gepas by God nie en moes deur versoeningsrites waar 'heel' diere plaasvervangend geoffer en bloed gestort is, in pas met God wat heilig en volmaak is, gebring word.

Die normale staat van 'n vrou, volgens die reinheidsisteem in die leefwêreld van die Bybel, is nie-menstrueel. In die antieke familiekultuur trou die ideale vrou in haar 
puberteit en bly min of meer konstant swanger of 'n voedende moeder. 'n Vrou wat dus menstrueer, geboorte gee, melk het wat uit haar borste loop, of 'n bloeding het, is nie haar normale, 'heel' self nie. Daarom word sy beskou as onrein (Countryman 1988:26). Tydens menstruasie is 'n vrou sewe dae lank onrein en haar onreinheid is so aansteeklik dat dit ander op 'n indirekte manier kan kontamineer, byvoorbeeld as hulle aan meubels sou raak waarop sy gelê of gesit het. Selfs wanneer menstruasie nie 'n faktor was nie, blyk dit dat vroue 'n groter moontlikheid het om te kontamineer as mans. Met die geboorte van 'n dogter bly die ma twee keer so lank onrein as met die geboorte van 'n seun (kyk Lev 12). Eksodus 19:10-15 berig dat, toe die Israeliete op die berg Sinaï hulleself gereed moes maak vir die verskyning van God, hulle beveel was om nie naby 'n vrou te kom nie. 'n Priester moes onreinheid vermy deur nie met 'n 'gebruikte' vrou te trou nie. Dit is 'n vrou wat verkrag is, geskei is of 'n weduwee is (vgl Lev 21:7, 14). Dit kan soos volg opgesom word: 'It is not too much to suggest that the texts demonstrate a general anxiety about the polluting potential of women' (Countryman 1988:29, 30).

Waarop die personaliteit van vrou-wees in die eerste-eeuse Mediterreense kultuur dus aankom, is dat vroue nie net ingebed was binne die patriargale sisteem nie, maar wyer nog, binne die struktuur van 'n reinheidsideologie. Om die plek van vroue in die Nuwe Testament te verstaan, behoort dit dus gekontekstualiseer te word in terme van hierdie sisteem en struktuur. Dit implikasie is dat vrou-wees vasgevang was in 'n stuktuur. Verantwoorde hermeneutiek vereis dat so 'n sistemiese vasgevangenheid nie gekontinueer mag word nie. Pastorale interaksie veronderstel die soeke na die bevrydende boodskap van die evangelie wat outentieke lewe voor God ten doel het. Pastorale interaksie behoort vroue bewus te maak van hulle identiteit as outentieke mens voor God. Jesus se bevryding van vroue uit sisteme en strukture wat vroue vervreem van hulleself, ander en God, vorm die perspektief hiervoor. In my volgende artikel gaan ek in op Jesus se interaksie met kulturele sisteme en in die besonder met vroue wat daarin vasgevang was.

\section{Literatuurverwysings}

Bach, A 1993. Reading allowed: Feminist biblical criticism approaching the millennium. Currents in Research: Biblical Studies 1, 191-215.

Countryman, L W [1988] 1989. Dirt, greed and sex: Sexual ethics in the New Testament and their implications for today. Second printing. Philadelphia: Fortress.

Dreyer, Y 1998. Pastorale interaksie met vroue: 'n Prakties-teologiese begronding. DD-proefskrif, Universiteit van Pretoria.

Hamerton-Kelly, R 1979. God the father: Theology and patriarchy in the teaching of Jesus. Philadelphia: Fortress. (Overtures to Biblical Theology.) 
Hanson, K C 1996. Kinship, in Rohrbaugh 1996:62-79.

Hooks, M 1985. Sacred prostitution in Israel and the ancient Near East. PhD Dissertation, Hebrew Union College.

Horsley, R A [1989] 1994. Sociology and the Jesus movement. Second edition. New York: Continuum.

Jacobs-Malina, D 1993. Beyond patriarchy: The images of family in Jesus. New York: Paulist.

Lenski, G, Nolan, P \& Lenski [1970] 1995. Human societies: An introduction to macrosociology. Seventh edition. New York: McGraw-Hill.

Malina, B J 1990. Mary - Woman of the Mediterranean: Mother and son. Biblical Theology Bulletin 20, 54-64.

- [1981] 1993. The New Testament world: Insights from cultural anthropology. Revised edition. Louisville, KY: Westminster/John Knox.

- 1996. Understanding New Testament persons, in Rohrbaugh 1996:41-61.

Malina, B J \& Rohrbaugh, R L 1992. Social Science commentary on the synoptic gospels. Minneapolis: Fortress.

Matthews, V H \& Benjamin, D C 1993. Social world of ancient Israel: 1250-587 $B C E$. Peabody, MA: Hendrickson.

Meyers, C L 1978. The roots of restriction: Women in Early Israel. Biblical Archaeology 41, 91-103.

Moxnes, H 1996. Honor and shame, in Rohrbaugh 1996:19-40.

Rohrbaugh, R (ed) 1996. The social sciences and New Testament interpretation. Peabody, MA: Hendrickson.

Rook, J 1998. When is a widow not a widow? Biblical Theology Bulletin 28/1, 4-6.

Stegemann, E W \& Stegemann, W 1995. Urchristliche Sozialgeschichte: Die Anfange im Judentum und die Christusgemeinden. Stuttgart: Kohlhammer.

Van Aarde, A G 1997. Social identity, status envy and Jesus' Abba. Pastoral Psychology 45/6, 451-472.

Van der Horst, P W 1993. Einige Beobachtungen zum Thema Frauen im antiken Judentum. Berliner Theologische Zeitschrift 9/1, 77-93.

Wuthnow, R, Hunter, J D, Bergesen, A \& Kurzweil, E 1987. Cultural analysis: The work of Peter Berger, Mary Douglas, Michel Foucault and Juergen Habermas. New York: Kegan Paul. 